\title{
Sustainable Agriculture for Environment Protection: Results of Six Years of Cooperation between China and Italy*
}

\author{
Maria Lodovica Gullino**1, Andrea Camponogara ${ }^{1}$, Nevio Capodagli ${ }^{1}$, Corrado Clini ${ }^{2}$ \\ ${ }^{1}$ Centro di competenza per l'Innovazione in Campo Agro-ambientale (AGROINNOVA), Università di Torino \\ Via Leonardo da Vinci 44, 10095 Grugliasco (To), Italy \\ ${ }^{2}$ Ministero dell'Ambiente e della Tutela del Territorio e del Mare
}

Received: 2 December 2006. Accepted: 2 January 2007

\begin{abstract}
The importance of a shift toward agricultural systems, which are more complex in terms of biodiversity in emerging countries such as China, where most of the population (about $60 \%$ ) lives in rural areas, in poor conditions and still relies on agriculture as the main source of income, is discussed. In China the problems caused by shifting to more intensive and polluting agricultural production patterns to address the demand for food of the growing population and by the need of higher incomes of rural communities are serious. The experience gained in the framework of the Sino-Italian Cooperation Program for Environment Protection jointly launched by the Italian Ministry for the Environment and Territory (IMET) and the State Environment Protection Administration of China (SEPA) in the year 2000, through the implementation of several cooperation projects in different rural areas of China is critically discussed.
\end{abstract}

Key-words: sustainable crop protection, international cooperation; sustainable development.

\section{Introduction}

Sustainable agricultural development is an important goal in economic planning and human development worldwide. Agriculture plays a significant role in protecting the environment and enhancing biodiversity (Altieri and Merrick, 1987; Paoletti, 2001; Marshall and Moonen, 2002) when it is carried out in a sustainable manner and takes into account its genetic resources. The three dimensions (economic, environmental and social) of sustainable development are highly visible in the agro-food sector: economic, environmental and social issues are probably more acute in this sector than in most of the other economic sectors. As a consequence, the agro-food sector is a major component (of course not the only one) of the overall issue of sustainable development and it is a highly relevant example of the main issues, which this topic at large can raise (Viatte, 2001). At present, agriculture faces the need to meet new challenges both in highly industrialized countries as well as in developing ones. Such challenges are represented by sustainable growth, social integration of rural communities and proper use of the advantages deriving from emerging global markets. These challenges go along with radical changes in the relation between society and agriculture. The experience gained in six years of cooperation with China is discussed.

\section{Agriculture in China}

China is a large agricultural country. The rural areas greatly contributed during the reform period to boost China's economic growth and social stabilization. In the early 1980s, the conversion from the collective system to the "Household Responsibility System" gave farmers autonomy in decision making and the right to bear profit or losses from their decisions. In the late 1980 s, the promotion of the establishment of

\footnotetext{
* Work carried out within the Framework Agreement between AGROINNOVA and Italian Ministry for Environment and Territory on "Sustainable agriculture".

** Corresponding Author: Tel.: + 39011 6708539; Fax: +39 011 6709307. E-mail address: marialodovica.gullino@unito.it
} 
Township and Village Enterprises provided a second contribution to China's growth and development, while avoiding massive migration from rural to urban areas. Nowadays the agricultural sector is declining, but still represents an important element of China's economy. Agriculture accounts for almost $15 \%$ of the GDP and above $40 \%$ of employment. Even though urbanization process goes at high speed, the $60 \%$ of the total population (1.3 billion people) keeps living in rural areas (OECD, 2005). Notwithstanding the still significant economic performance of the sector, China's agriculture faces grave challenges from both global economic integration and global changes in the natural environment. As a developing country with $9.6 \times 10^{6} \mathrm{Km}^{2}$ of land, China must acquire a good understanding of sustainable development, develop scientific methods for evaluating the sustainable capability of its agricultural lands, and deal with the issues of regional differences and imbalance in levels of agricultural development in order to devise strategies to achieve the goal of sustainable development across the country (OECD, 2005; Xu et al., 2006). The Chinese agriculture is living a challenging momentum. A set of interacting trends is making really difficult the conversion of conventional agricultural production patterns into sustainable ones.

China is relative scarce in agricultural land and water, having only the $10 \%$ of the world's arable land and its water resources per capita are around one quarter the world average. Overgrazing and misuse of water for irrigation are converting grassland and cropland into desert, mainly in the northern regions of China (i.e. Xinjiang and Inner Mongolia) and the North China Plain where grain production and grazing are more concentrated. The number of cattle, sheep and goats tripled between 1950 and 2003 while progressively reducing the protection effect of small vegetation against soil erosion by winds. In around fifty years, the annual loss rate of arable land due to desertification has more than doubled, passing from 156,000 hectares in 1950 to the current 360,000 hectares (Wang, 2004). The rapid industrialization that drives up demand contributes to shrink the cropland area. Cropland is being converted to non-farm uses at a record date, including industrial and residential construction and the paving of land and roads, highways and parking lots. Similar impressive trends are observed with regard to water tables. Rivers, wells and aquifers, mainly in northern China, are getting dry - some have already disappeared - with heavy recoil on agricultural production. In the North China Plain, the over pumping of water from aquifers also due to backlog irrigation techniques (e.g. flooding and furrow) set the depletion rate of groundwater levels at 1 to 3 meters a year.

Population is increasing at fast rate, nearly 15 million people annually. The efforts in tackling the higher demand of food are undermined by the decreasing trends in grain production. The phenomenal rise in China's production from 90 million tons in 1950 to 392 millions tons in 1998 comes to a halt. In 1998 it turned downward, falling to 322 million tons in 2003 (USDA, 2004). During the period 1992-2003, agricultural trade has shown a large increase in cereal imports in 1995 and 1996 and an increasingly high level of oilseeds imports since 1997. These decreasing trends are also due to radical dietary changes affecting both urban and rural population. With the improvement of welfare throughout the country and the general increase of per capita income, population started consuming less carbohydrates and more protein (meat, fruits, vegetables, eggs, fish). Reflecting changes in consumer demand, the composition of primary production continues to shift from crops to livestock and fish production. In 2003, crops accounted for $50 \%$ of the total agricultural production, livestock for $32 \%$, fishery for $14 \%$ and forestry for $4 \%$. While cereals remain the key crop, their share in total crop production and in the area sown declined quite substantially between 1990 and 2003, with other crops, such as vegetables and fruits, becoming more important and profitable (OECD, 2005).

The fast urbanization is cause of increasing social conflicts in rural areas. Agricultural incomes stop growing in real terms after 1996 and grew slowly after 1985 onwards, while incomes in urban areas continue to rise rapidly. The widening gap between rural and urban in terms of incomes and access to most social services is provoking a massive migration of rural workers - mainly young people - to urban areas. The actual number of people employed in agriculture declined between 1990 and 2000 by 28.5 million. The number of "floating" workers, workers with 
jobs in cities but registration in the countryside, is approaching 100 million. Over the next decade, another 100 million are likely to leave rural areas and the process probably will not stop until the rural workforce has been reduced to perhaps $10 \%$ of the total national workforce (Perkins, 2004). The migration of young farm workers to cities may halt the ongoing conversion to high value crops (i.e. vegetables, fruits, and grape) usually more labor-demanding. During the last decade the area of fruits and vegetable productions expanded by an average of 1.3 million hectares per year. In a country where $60 \%$ of the population lives in rural areas, in poor conditions, and still relies on agriculture as main source of income, the shifting to high-value crops is the only option for achieving a higher quality of life (Brown, 2005).

China's challenge to individuate sustainable solutions to social and economic pressure put on agriculture is even greater due to the threat posed by agriculture on environment and human health. China's agriculture represents one of the most polluting production sectors (CCICED, 2004).

Sanitary problems of agricultural produce worsen the general situation. About $10 \%$ of cereals, more than $20 \%$ of animal products and nearly half of the fruit and vegetable production are low quality. The rapid increase of animal production without a proper improvement of sanitary and veterinary conditions raised the degree of contamination of food by viruses, bacteria and other pathogens. The exceeding reliance on inorganic fertilizers drastically reduced the protein content of Chinese agricultural products, staple food of the 900 millions rural people. After China's accession to the WTO, safety concerns on Chinese products have been raised as potential barrier to the prospected increasing export of agro-food to Western countries, Europe in particular, because of its high quality and sanitary standards.

In the effort to reconcile economic and social needs and environmental protection China is undertaking countermeasures towards the promotion of sustainable agricultural practices. The attention paid to activities in the agro-environmental sector has been increasing over time due to the high social and economic priority attached by the Chinese authorities to the modernization of agriculture that must be pur- sued in a sustainable manner, addressing at once food security, environment protection, economic development, and good management of natural resources. On the one side, China is committed to comply with the multilateral environmental conventions and protocols with direct impact on the agricultural sectors; on the other side it is pushing the adoption of agricultural practices and technologies with low impact on the environment. Fifty-one special agricultural zones have been established by the Chinese government in order to concentrate the economic and technological investments. The Tenth Five-Years Plan (2001-2005) allocated more than 950 millions dollars to the improvement of agricultural infrastructures, the promotion of basic and applied research, the conversion to innovative technologies, the training of extension agents and growers. While priority is given to boosting grain production and to stop the increasing reliance on grain import, particular attention is paid to keep the positive trends registered during the last 10 years in fruit and vegetable production. Indeed, the area invested in fruits and vegetables passed from 10 millions hectares in 1991 to 26 millions hectares in 2003, mainly in response to a rapid growth in domestic demand and in the export market. In a country like China where the average farm surface is around 0.65 hectares, the shifting to higher value crops remains the only solution to increase salaries. Although modernization is occurring mainly in the traditional agricultural sectors, other emerging sectors such as organic farming are drawing attention of policy makers as promising both in terms of export and sustainability. Nowadays organic farming in China represents only $0.4 \%$ of the total agricultural area, far below the European average of $3.5 \%$. However organic food production is estimated to increase by 10 times over the next decade. The value of trade in exports of organic products that jumped from 300,000 dollars in 1995 to 120 million dollars in 2003 is expected to further increase in the future at an annual rate of $30 \%$ (Xie et al., 2005).

\section{The agriculture cooperation projects in China}

The Chinese government has been paying a great deal of attention to the concept of sustainable development by listing it as a signifi- 
cant goal in the $21^{\text {st }}$ Century China Agenda (National Planning Committee, 1994). In the past decades, considerable research has been carried out by Chinese researchers and governmental agencies as well as by some international agencies and foreign researchers, to address the issues that China is facing (Gullino et al., 2006). According to the data of the Chinese Ministry of Commerce, foreign direct investments in agriculture almost doubled from 2002 to 2003, passing from more than 0.7 billion US dollars to around 1.4 billions, and stabilized at 1.2 billions in the year 2004. International multilateral institutions (e.g. the World Bank, IFAD, FAO, UNDP, the Asia Development Bank, etc.) represented the first channel of foreign capitals, followed by bilateral technical and economical cooperation between governments, and collaboration at enterprise level. A growing trend of projects linking agriculture to environmental protection and sustainable development at large has been registered during the recent years. Agriculture is not addressed anymore as a stand alone sector. On the contrary its deep interconnections to the societal, economical and environmental aspects of sustainable development projects objectives are recognized shifted from agriculture per se to agro-environment, intended as a complex dimension where food production "internalizes" the principles of environmental protection and sustainable development. Particularly in emerging countries like China that achieved acceptable levels of food production, cooperation in agriculture is not regarded anymore as a matter of food security, but as a fundamental occasion to develop sustainable models of production, ensuring protection and conservation of natural resources and improvement of quality of life in rural areas.

The agro-environmental projects implemented within the Sino-Italian Cooperation Program for Environmental Protection, a framework program jointly launched in 2000 by the Italian Ministry for Environment and Territory and China State Environmental Protection Administration for the realization of demonstration and technology transfer projects, reflect this changing trend (Gullino et al., 2006).

Under such umbrella, all agro-environmental projects implemented respond to the primary goal of reducing China's reliance on a massive use of fertilizers and pesticides that is pos- ing serious threats to global environment and causing exceptional phenomena of soil erosion and water pollution within the Chinese borders. While the general effort is to enable China's compliance with the obligations set by the Multilateral Environmental Agreements and with the Millennium Development Goals, project objectives and instruments of implementation have to be site specific and to properly address the particular social and economic needs of the area of interventions. In large developing countries like China, with an extremely diversified agricultural sector in terms of climate, levels of infrastructure and mechanization, economic and social conditions, it is furthermore important avoiding generalized approaches.

Since the launch of the Sino-Italian Cooperation Program, significant investments have been made for the phasing out of methyl bromide, a highly toxic fumigant used in the horticultural sector for pre-plant soil disinfestation and banned by the Montreal Protocol because of its implication in the ozone layer depletion (Gullino et al., 2003). Pilot activities aimed at demonstrating the technical and economic feasibility of innovative and low environmental impact techniques for soil disinfestation started in 2001 in Shandong and Hebei provinces with the final objective to individuate solutions replicable in other areas of China. The positive project outcomes eventually contributed to the definition of China's MB National Phase-out Plan under the framework of the Multilateral Fund of Montreal Protocol. While the choice of target areas went quite automatically to Hebei and Shandong provinces because of their high methyl bromide consumption and characterized by an expanding horticultural sector, the selection of target technologies took fully into account the local level of infrastructure, mechanization, availability of agricultural inputs and know-how. Solutions like soil steam pasteurization and soilless cultivation systems were ruled out in favor of cheaper alternatives, easier to apply and less energy consuming. Soil solarization, the use of grafting on resistant rootstocks and the application of less harmful chemicals at reduced dosages via drip irrigation, tested on tomatoes and strawberries, resulted of higher acceptance by local growers because while providing level of treatment effectiveness comparable to methyl bromide, they require lower cost 
of investment and small changes to fit within the traditional cultural practices (Cao et al., 2002a; Cao et al. 2002b). For these reasons, they were registered by the Chinese Ministry of Science and Technology as successful cases suitable to Chinese agriculture for the control of soilborne pathogens and as effective alternatives to the use of methyl bromide.

The same approach, avoiding pursuing shortterm objectives due to the pressure for profit was adopted in different regions, in order to ensure the reproducibility and long-term sustainability of transferred technologies. In Xinjiang and Inner Mongolia, for instance, Chinese western regions characterized by poor social conditions, a very low level of infrastructure and scarce capacity of farmers in managing modern cropping systems, the choice went to very basic and low cost technologies. Drip irrigation systems resulted as a win-win solution to the serious problems of desertification, soil erosion and pollution affecting the two regions. Used in substitution of the locally adopted flood irrigation and also for the distribution of fertilizers at reduced dosages, drip irrigation systems permitted to achieve significant reduction in the use of water and fertilizers (5-6 times less compared to common practices) on tomatoes, pumpkins, cabbages, grapes and corn. These were promising outcomes for regions like Xinjiang, formerly one of the poorest regions of China and now preparing to be one of the main agricultural production areas of the country. Different considerations should be made on the use of starchbased biodegradable plastic films used in replacement of traditional polyethylene mulching films, cause of problems of "white pollution" in the area. The agronomic and environmental performance was satisfactory: a good control of weeds and a complete degradation of the film few months after the end of the cropping cycle were observed. However, since the cost of biodegradable plastic is still too high in comparison with traditional plastic films their actual transfer into practice must be considered in the very long term (Gullino et al., 2002). Differently from Xinjiang and Inner Mongolia, more specialized technologies and complex cropping systems were considered by the project implemented in Chongnming (Shanghai). The Shanghai area is the most advanced in China as for technology, know-how, foreign trade and capital turnover. The expectation in terms of technology transfer is quite high.

In Chongming Island, the third biggest Island of China after Taiwan and Hainan a few kilometers from Shanghai, IMET and the Shanghai Municipal Government are implementing a project meant to convert the traditional local agricultural systems into organic farming production. Chongming Island is the world's largest alluvial island. Its coastal wetland and tidal flats provide many important ecological services including buffers against tidal surges and staging areas for migratory birds. Due to its extraordinary resources, scenic qualities, and its proximity to the city of Shanghai, $45 \mathrm{~km}$ away, the island is also an attractive tourist destination, and it supports important agricultural and fisheries economies. The aim is to develop environmentally friendly green food production not only to increase potential for higher income for local growers looking with interest to foreign markets, but also to enable the production of healthy food and the promotion of a safe environment for national eco-tourists visiting in future Chongming Island. In particular the project aims at stopping soil salinization processes, to reduce the use of chemical fertilizers (currently far over the national safety limit of $225 \mathrm{~kg} \mathrm{ha}^{-1}$ ) and pesticides. In two-year field experimental trials on tomatoes, watermelons, pumpkins, horse beans and other horticultural crops, technical and economical feasibility of the use of tolerant and resistant varieties, grafting on resistant rootstocks, biodegradable mulching films in combination with the use of fertigation and environmental monitoring systems, and integrated pest management also based on the use of biological products will be evaluated. The project goes beyond the merely environmental concerns and strengthens the role of rural areas as multifunctional dynamic systems. This is an important aspect in China, since the present economic growth, urbanization and increased leisure time, also increase the demand for tourism and recreation activities in rural areas. Considering the future development plan of Chongming Island as the first Ecological Recreational Island of China, the organic production of high value crops (vegetable and fruits) is regarded as a means to link higher income and market opportunity to environment protection (Gullino et al., 2006). 
The selection of vegetables and fruits as target crops represents a constant in all the agroenvironmental projects of the Sino-Italian Cooperation, due to environmental and economic reasons. While grains remain the key crop in China, their share on total crop production and on the area sown declined quite substantially between 1990 and 2003 as other crops, like fruit and vegetables, became more profitable and the government relaxed most of the policy measures, which had previously forced farmers to produce cereals (OECD, 2005). However, if on the one hand changes in the domestic demand and emerging export opportunities guided the impressive increase in vegetable and fruit production and provided farmers with more margin for higher income, on the other hand the shifting of Chinese agricultural production from grains to horticultural crops, notoriously demanding higher amount of chemical inputs, is likely to worsen the increasing consumption trend of fertilizers and pesticides. It is therefore urgent to take effective and immediate actions for the development of a horticultural sector able to take environmental externalities into account.

The lack of technical and scientific knowhow, and capacity in managing innovative cropping systems emerged as one of the major barriers towards the actual adoption of transferred technologies. The results from the Sino-Italian agro-environmental projects do not surprise as they reflect the general Chinese situation. Although there is an urgent need to create new profiles of researchers and extension agents supporting in the long term the conversion to sustainable agricultural practices, investments in agricultural research and education are at minimum levels while the Chinese extension system is hardly seeking a new balance after conversion from the central planning systems to the "Household Responsibility Systems", which claimed individual farmers as the basic production unit, instead of the production brigade of the previous collective systems. The challenge is to re-orient scientific and technical capabilities towards the market and industry requirements. Again, international cooperation programs play a fundamental role in filling the educational gap.

All demonstration projects implemented within the Sino-Italian cooperation projects provide back-to-back with technology transfer a full package of training activities particularly tailored on the specific needs of local farmers and technicians, but involving also academic institutions and private companies in the attempt to establish cross-sectorial partnerships. Particular emphasis is given to the scientific collaboration with academic institutes and research centers. At the micro level, there is a need for China's higher education institutions to learn how to identify, develop, and implement research and extension programs well adjusted to the global and domestic scenario. At the macro level, there is a need for China's policymakers to consult experts in order to formulate appropriate sustainable development strategies and policy. In this perspective, strengthening capacity and efficiency of the role of universities towards government, industry and market operators is strategic for the future sustainable development of Chinese agriculture and the promotion of innovative "green" technologies. Several Sino-Italian cooperation projects are pursuing this objective.

Joint research programs have been established between Italian and Chinese universities with the aim of making Chinese scientists and technicians more acquainted with some of the modern techniques targeted by the demonstration projects. The use of biocontrol agents and grafting on resistant rootstocks within integrated pest management systems is addressed by the project "Sustainable plant protection in respect of the environment: modern techniques for the control of plant pest and diseases of horticultural crops in China". Within the Scientific and Technological Cooperation Program between the Italian Ministry of Foreign Affairs and the Chinese Ministry of Science and Technology, a replicable model of research and semi-commercial scale application of innovative techniques and technologies for organic agricultural waste composting as well as of the use of biodegradable plastics as a means to reduce production of non-compostable agricultural waste is being developed under the project "Innovative techniques for reduction and recycling of agricultural wastes". A project co-financed by the European Commission in the framework of the Asia-Link Programme will promote sharing of technical, scientific, economical and ethical knowledge on organic farming, while a new project co-financed by the Italian Ministry of Educa- 
tion, University and Research will permit research on molecular diagnostic techniques for plant pathogens, prevention of food contamination by mycotoxins, recycling of industrial organic wastes for compost production and influence of climate change on the diffusion of plant diseases.

The involvement of the private sector is particularly sought. Each project is implemented on a participatory basis, stimulating the creation of broad partnerships involving all relevant stakeholders, from governmental agencies to NGOs, from academic institutes to private companies. The model followed is that of Type II Partnership emerged from the 2002 Johannesburg World Summit on Sustainable Development as a means to promote a full integration of public and private sectors at large in the multilateral and bilateral cooperation programs, both in technical and financial terms. It is worth underlining, as an example, that the academic partnership between Italian and Chinese academic institutes, consolidated over 5 years of activities within the framework of the Sino-Italian Cooperation Program, eventually showed high capacity to convey human and financial resources from private and public sectors into the development of broader mobility programs. Only in the year 2005, thanks to the exploitation of different sources of co-financing, the number of students and researchers visiting Italian firms and research institutes for study and research activities on sustainable agriculture within MSc and $\mathrm{PhD}$ programs jumped from few units to over 50 people, and the period of staying from few weeks to 3 years.

Nevertheless, it is still quite difficult to plan the involvement of the private sector in longterm programs and give cooperation projects also a market perspective, facilitating the introduction and commercialization of environmentally friendly innovative technologies in China. Due to the fragile Chinese regulation framework on intellectual property protection, the involvement of Italian private companies is often limited to stand-alone interventions within each single project (e.g. field visits, lectures during seminars and training, short-term internships and technology procurement). Even though is offered the possibility to piggy-back on a governmental program like the Sino-Italian Cooperation Program for Environmental Protection and create effective synergies mutually benefit- ing both sides, the skepticism showed by private firms about a not yet conducive Chinese regulatory system represents a great barrier against an effective technology transfer. First signals of potential cooperation fully involving Chinese and Italian private companies in the development of innovative technologies for agriculture have been shown by the already mentioned project "Sustainable plant protection in respect of the environment: modern techniques for the control of plant pest and diseases of horticultural crops in China”.

\section{Concluding remarks}

A study carried out by Xu et al. (2006) by zoning China into nine regions and 22 sub-regions, depicted Chinese agriculture in the year 2000, and showed that 16 provincial units have reached a level of sustainable development. Most of the agricultural projects carried out within the Sino-Italian cooperation program interested areas needing support. Being such projects fully integrated within a broader sustainable development program (Clini et al., 2007), they were able to involve all stakeholders in both project preparation and implementation. Particularly, governmental Institutions, Academic institutions, public research centers and private companies have always been partnered with the aim to create a long lasting network of local and international researchers and experts supporting the development and the adaptation of sustainable farming systems as well as the design of a new regulatory framework supporting the adoption of innovative technologies.

Important in all cooperation projects have been training and information activities to enable the actual transfer into practice of target sustainable agricultural technologies and practices. District workshops and seminars have been organized in order to keep people involved in project activities continuously aware of all progress as well as to inform stakeholders on scientific, technical and economic feasibility of upcoming new techniques and systems. Education and training are part of any strategy to promote the adoption of appropriate technologies and farm management practices: all the projects implemented included exchange of MSc and Ph.D. students as well as of researchers among the Research Institutions involved. The 
experience gained through the implementation of cooperation projects in rural areas of China shows the strategic role that sustainable agriculture plays towards the promotion of sustainable development (Gullino et al., 2006). Moreover, the projects implemented respond to the need of creating job opportunities alternative to the agricultural sector. In this respect, agrotourism is a valued option protecting the rural environment, sustaining small-sized enterprises and providing income and job opportunities.

In conclusion, the synergic role provided by the different projects in promoting environment protection and sustainable agriculture at once, will represent a strong effective effort toward the rural development of different regions. Such broader approach recognizes the multi functionality role of agriculture accordingly with the objectives of Agenda 21 and should represent an example for similar cooperation initiatives likely to be implemented.

\section{References}

Altieri M.A., Merrick L.C. 1987. In situ conservation of crop genetic resources through maintenance of traditional farming systems. Economic Botany, 41:86-96.

Brown L.R. 2005. Reversing China's harvest decline. In: Earth Policy Institute (eds.): Outgrowing the Earth, 133-155. W.W. Norton \& Company Inc., New York.

Cao A., Guo M., Cao Z., Zheng C., Gullino M.L., Camponogara A., Minuto A. 2002a. Sustainable practices for soil disinfestation: a project between Italy and China. Proceedings $2^{\text {nd }}$ International Conference on Sustainable agriculture for food, energy and industry, Beijing, 2002, vol. 2, 1492-1500.

Cao Z., Yu Y., Chen G., Minuto A., Camponogara A., Gullino M.L. 2002b. Ecological studies on nematodes in alternative technologies to the use of methyl bromide in soil fumigation. Proceedings $2^{\text {nd }}$ International Conference on Sustainable agriculture for food, energy and industry, Beijing, 2002, vol. 1, 85-92.

CCICED - Agricultural and Rural Development Task Force 2004. China's Agricultural and Rural Development in the New Era: Challenges, Opportunities and Policy Options. Policy briefs.

Clini C., Gullino M.L., Musu I. (eds.) 2007. Sustainable development and environment protection. Springer, in press.

Gullino M.L., Camponogara A., Clini C., Yi L., Guanghui X., Xiaoling Y. 2002. Sustainable agriculture for environment protection: a Sino-Italian Cooperation Program. Proceedings $2^{\text {nd }}$ International Conference on Sustainable agriculture for food, energy and industry, Beijing, 2002, vol. 1, 948-952.
Gullino M.L, Camponogara A., Capodagli N. 2007. Sustainable agriculture for environment protection: cooperation between China and Italy. In: Clini C., Gullino M.L., Musu I., Xiaoling Y. (eds.): Sustainable development and environment protection.

Gullino M.L, Camponogara A., Capodagli N., Xiaoling Y., Clini C. 2006. Sustainable agriculture for environment protection: cooperation between China and Italy. Journal of Food, Agriculture \& Environment, 4:84-92.

Gullino M.L., Camponogara A., Gasparrini G., Rizzo V., Clini C., Garibaldi A. 2003. Replacing methyl bromide for soil disinfestation. The Italian experience and implication for other countries. Plant Disease, 87:1012-1021.

Marshall E.J.O., Moonen A.C. 2002. Field margins in Northern Europe: their functions and interactions with agriculture. Agriculture, Ecosystems and Environment, 89:5-21.

Nyberg A., Rozelle S. 1999. Accelerating China's rural transformation. From The World Bank: http://wwwwds.worldbank.org/servlet/WDS_IBank_Servlet?pco nt =details\&eid=000094946_99111006010783.

OECD 2005. OECD Review for Agricultural Policies China. OECD Publishing, Paris.

Paoletti M. 2001. Biodiversity in agroecosystems and bioindicators of environmental health. In: Shiyomi M., Koizumi H. (eds.): Structure and function in agroecosystems design and management. Advances in Agroecology, 11-41. CRC Press, Boca Raton, USA.

Perkins D. 2004. Declining Growth in Farm Output and Employment. Implications for China's Economy and Society. Retrieved April, 2006, from Harvard University Website: http://post.economics.harvard.edu/faculty/ perkins/papers/farmoutput.pdf

US Congress 1990. Food, agriculture, conservation and trade act. US Congress Papers, Title XVI, Research, Subtitle A, Section 1602.

U.S. Department of Agriculture 2004. Production, Supply and Distribution (electronic database). Retrieved March, 2005, from USDA web site: http://www.fas.usda.gov/psd.

Viatte G. 2001. Agriculture and sustainable development: a societal and policy challenge. Proc. Third Congress of the European Society for Agricultural and Food ethics, 97-102.

Wang T. 2004. Progress in sandy desertification research of China. Journal of geographical sciences, 14:387-400.

Xie B., Li T., Zhao K., Xi Y. 2005. Impact of EU organic-certification regulation on organic exports from China. Outlook on Agriculture. 34:141-147.

Xu X., Hou L., Lin H., Liu, W. 2006. Zoning of sustainable agricultural development in China. Agricultural Systems, 87:38-62.

Zimdhal R.L. 2002. Moral confidence in agriculture. American Journal of Alternative Agriculture, 17:44-53. 